\title{
O CONGRESSO E A RENDA EMERGENCIAL
}

\section{THE CONGRESS AND THE RENDA EMERGENCIAL (BRAZILIAN EMERGENCY AID)}

\section{EL CONGRESO Y LA RENDA EMERGENCIAL (AYUDA DE EMERGENCIA BRASILENA)}

\author{
Sergio Simoni $\mathrm{Jr}^{1}$ \\ Hellen Guicheney ${ }^{2}$ \\ João Lucas Sacchi Oliveira ${ }^{3}$
}

Resumo: Quem é responsável pelo Auxílio Emergencial? A imprensa e alguns analistas políticos ressaltam que foi o Congresso Nacional, e não o Presidente da República (junto a seus líderes parlamentares), que liderou a formulação daquela que seria a principal política adotada no contexto da pandemia de Covid- 19 . Ainda assim, é corrente a opinião de que Bolsonaro, mesmo passivo diante da iniciativa legislativa, recolheria dividendos de apoio na opinião pública pela distribuição do auxílio. Neste artigo, damos um passo atrás nesse debate e, a partir da análise de projetos de lei, emendas e debates parlamentares, argumentamos que não se pode tomar o Congresso como um ator unitário. Antes, as deliberações revelam disputas ideológica-partidárias com implicações distributivas e, por conseguinte, para a construção de bandeiras eleitorais.

Palavras-chave: Políticas Sociais; Relações Executivo-legislativo; Legislativo; Covid-19; Renda Básica Emergencial

\begin{abstract}
Who was responsible for creating the Auxílio Emergencial (Brazilian emergency aid)? The press and some political analysts point out that it was the National Congress, and not the President of the Republic (along with its parliamentary leaders), who led the formulation of what would be the main policy adopted in the context of the Covid-19 pandemic. Still, there is a current belief that, regardless of the authorship, it is Bolsonaro who, despite being passive or absent in the use of his own legislative powers in this matter, would collect most of the public opinion dividends of the Auxílio Emergencial. In this article, we take a step back and pose a serious question to such reasoning. Based on the analysis of bills, amendments and parliamentary debates, we argue that Congress should not be taken as a unitary actor. Instead, the deliberations reveal ideological-party disputes with distributive implications and, therefore, for the construction of electoral flags.
\end{abstract}

Keywords: Social Policies; Executive-Legislative Relations; Legislative; Covid-19; Emergency Basic Income

\footnotetext{
${ }^{1}$ Professor de Ciência Política e de Políticas Públicas da UFRGS. Doutor em Ciência Política pela USP. É pesquisador do Centro de Estudos da Metrópole (CEM), do Centro de Estudos de Opinião Pública (CESOP), do Núcleo de Pesquisa e Documentação da Política Rio-Grandense (NUPERGS) e da Rede de Pesquisa Solidária. Membro da comissão editorial da Revista Brasileira de Ciências Sociais (RBCS).

${ }^{2}$ Pós-doutoranda do IESP/UERJ. Doutora em Ciência Política pela USP, mestre e bacharel pela UFMG. É pesquisadora do Centro de Estudos da Metrópole (CEM), do Centro Brasileiro de Análise e Planejamento (Cebrap), da Rede de Pesquisa Solidária e, no IESP, dos núcleos Necon e Doxa.

${ }^{3}$ Mestrando da FDUSP. Colaborador do Projeto Temático Fapesp (2015/26662-5) "Gestão de Incertezas em Atividades de Inovação", da Rede de Pesquisa Solidária, e do Center for Artificial Intelligence (C4AI). Advogado e assistente parlamentar na Alesp.
} 
Resumen: ¿Quién fue el responsable por la creación del Auxílio Emergencial (ayuda de emergencia brasileña)? La prensa y algunos analistas políticos señalan que fue el Congreso Nacional, y no el Presidente de la República (e sus líderes de gobierno), quien lideró la formulación de la que sería la principal política adoptada en el contexto del Covid-19. Aún así, existe la creencia actual de que, independientemente de la autoría, es Bolsonaro quien, a pesar de ser pasivo o ausente en el uso de sus propios poderes legislativos en esta materia, recaudaría la mayor parte de los dividendos de la opinión pública a respecto del Auxílio Emergencial. En este artículo, damos un paso atrás y planteamos una seria pregunta a tal razonamiento. A partir del análisis de proyectos de ley, enmiendas y debates parlamentarios, argumentamos que el Congreso no debe ser tomado como un actor unitario. Ao contrario, las deliberaciones revelan disputas ideológicopartidistas con implicaciones distributivas y, por tanto, para la construcción de banderas electorales.

Palablas clave: Política social; Relaciones ejecutivo-legislativo; Legislativo; COVID-19; Ingresos básicos de emergencia

\section{Introdução}

Uma das principais políticas adotadas no Brasil para combater as graves consequências socioeconômicas da epidemia de Covid-19 é a Renda Básica Emergencial (RBE), também conhecida como Auxílio Emergencial (Lei 13.982/2020) ${ }^{4}$. O principal objetivo da medida consiste em garantir um aporte de renda, em caráter emergencial e temporário, a uma parcela da população tradicionalmente vulnerável, ou que se tornou vulnerável durante a pandemia em decorrência da redução do número de postos de trabalho disponíveis, da retração da atividade econômica ou da própria dificuldade de exercer atividade informal diante do contexto de distanciamento social.

A referida política de transferência de renda incondicional estabeleceu, em abril de 2020, o pagamento mensal de $\mathrm{R} \$ 600,00$ para indivíduos sem emprego formal ativo e que cumprissem a alguns critérios adicionais de elegibilidade ${ }^{5}$. O benefício foi inicialmente estabelecido para ter duração de 3 meses, mas foi renovado mais de uma vez - sendo que, a partir de setembro, com nova legislação que reduziu seu valor para $\mathrm{R} \$ 300,00$, além de estabelecer critérios de elegibilidade mais estritos ${ }^{6}$. Beneficiários do Programa Bolsa Família (PBF) foram transferidos e milhões de novas pessoas foram incorporadas, atingindo um patamar quantitativo único na história das políticas sociais no Brasil, com efeitos consideráveis para a redução da pobreza (BARBOSA \& PRATES, 2020; REDE DE PESQUISA SOLIDÁRIA, 2020a), além de alegados efeitos positivos para a economia (FREIRE, et al., 2020).

\footnotetext{
${ }^{4}$ Nesta frase, a política é tratada como existente no tempo presente ("é") dado que o artigo foi redigido em fins de 2020 , enquanto o programa ainda estava em vigor e previsto para perdurar até dezembro do mesmo ano, ainda que na modalidade de "Auxílio Emergencial residual", como falamos adiante.

${ }^{5}$ Ao início do programa, eram requeridos: que os indivíduos fossem maior de 18 anos (alteração posterior admitiu mãe menor de idade) não fossem titulares de benefício previdenciário, assistencial ou de transferência de renda (salvo o Bolsa Família); que tivessem renda familiar mensal per capita de até $1 / 2$ salário-mínimo ou total de até 3; que não tivessem recebido, em 2018, rendimentos tributáveis acima de $\mathrm{R} \$ 28.559,70$; que exercessem atividade como microempreendedor individual (MEI), fossem contribuinte individual do Regime Geral de Previdência Social (RGPS) ou trabalhadores informais.

${ }^{6}$ Medida Provisória n ${ }^{\circ} 1.000$, de 2 de setembro de 2020.
} 
A imprensa relata amplamente que o principal ator responsável pela formulação e aprovação do auxílio em março de 2020 foi o Congresso Nacional, e não o presidente da República. Segundo visão majoritária dos grandes veículos, Bolsonaro (sem partido) e seus líderes congressuais não teriam organizado a pauta legislativa com vistas a aprovar a RBE, e, quando inicialmente o fizeram, propuseram um benefício de menor magnitude, de $R \$ 200,00$, segundo as orientações do Ministro da Economia Paulo Guedes ${ }^{7}$. Mais do que isso, em boa parte do tempo o presidente se mostrou ambivalente em defesa da política. Surpreendentemente, isso se deu contrariamente ao ocorrido em outros países, inclusive nos EUA, cujos chefes do executivo lideraram a aprovação ou reformulação de políticas sociais emergenciais de combate ao coronavírus ${ }^{8}$.

O fenômeno se torna analiticamente ainda mais intrigante quando se considera que é corrente entre os analistas a ideia de que, mesmo passivo diante da iniciativa do congresso, Bolsonaro recolheria dividendos de apoio na opinião pública pela distribuição do auxílio9. Esse raciocínio toca em importantes questões caras à Ciência Política: quais são os mecanismos que transformam políticas em votos? Que ator se beneficia? Quem implementa a política é alvo de retornos positivos, independente da formulação ou da construção de discursos políticos favoráveis ou contrários?

Consideramos que, para compreensão da disputa política em torno da RBE, é adequado dar um passo anterior. Argumentamos neste texto que a afirmação de que o congresso seria o principal responsável pela aprovação original da RBE, ainda que verdadeira, esconde uma dimensão importante. O legislativo é composto de vários partidos de ideologias diferentes e eleitoralmente rivais. E, ainda que muitos consensos tenham se manifestado dentre os congressistas para a aprovação do auxílio, ressaltamos que clivagens relevantes também emergiram em aspectos específicos do desenho da política. Esses conflitos expressam diferentes visões sobre os contornos de uma política social, e se relacionam, direta e indiretamente, com o debate sobre quem ficará com os dividendos eleitorais do auxílio.

Nossos argumentos são embasados em dois conjuntos de teorias desenvolvidas no interior da ciência política: (i) um que ressalta a importância da consideração da heterogeneidade interna ao parlamento para compreensão do funcionamento do processo decisório; (ii) e outro que ressalta que, frequentemente, o principal locus da disputa política consiste nos aspectos de desenho interno das políticas sociais, sobretudo as de transferência de renda.

\footnotetext{
${ }^{7}$ Ver, e.g., texto do Estado de Minas (https://tinyurl.com/y2tzfufr) e do El País Brasil (https://tinyurl.com/y3a5lec7).

${ }^{8}$ Ver, e.g., textos do New York Times (https://tinyurl.com/y2p8ueur). Dos 67 países da OCDE e da América Latina e Caribe, 46 criaram ou expandiram programas de transferência de renda durante a pandemia. Agradecemos a Vítor Menezes por compartilhar essas informações.

9 Ver, e.g., textos publicados no Nexo (https://tinyurl.com/yyrwlpuw) e no Valor Econômico (https://tinyurl.com/yxu6vbsu).
} 
Neste primeiro passo de nossa agenda de pesquisa focada na tramitação da RBE, mostramos que definições sobre critérios de elegibilidade, valor e duração do benefício, além dos mecanismos de implementação, revelam disputas ideológica-partidárias com implicações distributivas e, por conseguinte, para a construção de bandeiras eleitorais. A análise é baseada em extensa avaliação documental da tramitação, na Câmara e no Senado, tanto do PL 9236/2020, que institui o auxílio emergencial, quanto do PLS 873/2020, aprovado logo depois propondo alterações. Também são analisados todos os vetos parciais expressos pelo Executivo, além de uma lista exaustiva dos projetos associados à política apresentados posteriormente. Mais especificamente, verificamos a distribuição ideológica da autoria de cada projeto e emenda apresentados (se esquerda, centro ou direita) em relação a diferentes elementos do desenho da referida política social - (i) valor; (ii) critérios de elegibilidade; (iii) prazo de duração do benefício (no de parcelas); (iv) modo de implementação; (v) reforço da apuração e punição para beneficiários irregulares; (vi) se propunha uma política nova.

Os resultados da análise mostram que, a despeito da célere aprovação da política, a esquerda foi mais atuante na defesa de um benefício de maior valor e prazo, além de focar mais nas questões relativas à facilitação da implementação e à expansão dos critérios de elegibilidade - propostas estas que muitas vezes não foram acatadas por parlamentares de direita, o que explicita a existência de conflito em aspectos relativos ao desenho da política. Já nas conclusões, sugerimos, como uma hipótese a ser testada num próximo esforço de pesquisa, que essas diferenças podem ter consequências eleitorais de longo-prazo.

Na sequência desta Introdução, é apresentado o arcabouço teórico. Então, passamos à análise empírica, chamando atenção para consensos e dissensos nas preferências expressas pelos atores políticos tanto no projeto que originalmente gerou a RBE, quanto nas propostas de modificação da lei. Ao final, concluímos com uma síntese dos achados, além de propor uma hipótese para continuação da agenda de pesquisa.

\section{Clivagens internas no Congresso e o desenho de políticas públicas}

É comum na opinião pública - e mesmo entre analistas ou em parte do debate acadêmico - a busca por interpretar a vontade, intenção ou preferência "do legislativo" quando se trata de resultados de decisões parlamentares. Ainda que expressões como esta possam ser usadas como uma espécie de atalho de linguagem, é importante ter consciência de sua limitação cognitiva. Como ressalta Shepsle (1992), tomar como verdadeiras expressões como essa incorreria em falácia ou na crença de uma espécie de mito. Os resultados das tramitações e deliberações não expressam uma vontade majoritária única e discernível, antes, são fruto de reiteradas barganhas, conflitos e estratégias. Mesmo intra bloco vencedor (maioria) ou perdedor (minoria) permeia heterogeneidade. 
Diversos estudos sobre o caso brasileiro mostram que o legislativo seria dividido por uma clivagem básica, ditada pelas relações dos partidos com o executivo por meio da composição do ministério. Em poucas palavras, pelo conflito entre coalizão e oposição (FIGUEIREDO E LIMONGI, 2009; IZUMI, 2016). No entanto, não se deve interpretar que partidos sejam guiados unicamente por cargos. Estudos posteriores ressaltam que existem disputas internas a esses dois grandes blocos - guiadas por preferências político-ideológicas e cálculos eleitorais conformando o funcionamento do parlamento brasileiro (ARAÚJO, 2017; INÁCIO E REZENDE, 2015; FREITAS, 2016) ${ }^{10}$. Logo, decisões parlamentares não podem ser vistas como expressão da vontade "do legislativo", como ente único. Antes, como fruto de um conjunto de alianças, mas também de conflitos, disputas e tentativas de controle dos diferentes partidos partidos estes que se veem guiados não apenas pela disputa e manutenção de cargos, mas também pela definição de políticas públicas.

No caso da tomada de decisão sobre a RBE, em particular, alguns aspectos relacionados ao controle das disputas entre os partidos devem ser considerados. Primeiro, os padrões relatados acima de relacionamento interno à coalizão e, também, entre o governo e a oposição, são fruto da observação de governos que formalmente montam e gerenciam uma coalizão, o que não pode ser dito em relação ao governo Bolsonaro, ao menos não até meados de 2020 (ou seja, após a aprovação da renda emergencial). Cabe lembrar, a esse respeito, que o presidente rompeu até com seu próprio partido. Segundo, particularmente sobre políticas de transferência de renda, da qual o auxílio emergencial é um tipo específico, a literatura ressalta que os principais embates muitas vezes não incidem na defesa de sua aprovação ou reprovação, mas sim sobre aspectos do desenho das propostas que são apresentadas. Políticas sociais desse tipo podem ser consideradas "pacotes" ou "modelos" que comportam diferenças internas em seus arranjos (FISZBEIN E SCHADY, 2009; CECCHINI E MADARIAGA, 2011), materializando diferentes visões sobre o papel do Estado e do mercado na distribuição de renda. Neste sentido, enquanto alguns programas são concebidos como uma ajuda pontual e temporária, concedendo ênfase às "portas de saída" (caso do chileno Chile Solidario); outros buscam a integração dos vulneráveis a uma rede de políticas sociais mais ampla (caso do uruguaio PANES). Ou seja, o impacto distributivo de uma dada política social pode variar significativamente de acordo com o desenho específico que for adotado para ela. Aprofundando o insight de Lowi (1972), pode-se dizer, mesmo, que um único modelo de política pública pode comportar, dada a diversidade em seus arranjos internos, conflitos políticos diferentes.

Dessa forma, levando em consideração a gestão de governo por Bolsonaro e a plasticidade do desenho das políticas de transferência de renda, defendemos que a compreensão adequada sobre o papel do congresso na deliberação e aprovação do auxílio emergencial exige ressaltar as

\footnotetext{
${ }^{10}$ Expressas, por exemplo, em propostas de fiscalização e controle; no uso estratégico de relatorias e presidência de comissões; dentre outros mecanismos.
} 
clivagens ideológicas existentes. Para proceder à classificação ideológica dos autores dos projetos e emendas analisados, utilizamos a classificação partidária exposta no texto de Codato, Berlatto e Bolognesi (2018), que compreende, a saber: (i) Direta: Avante, DEM, Novo, Patriota, PL, Podemos, PP, PSC, PSD, PSL, PTB, Republicanos e Solidariedade; (ii) Centro: Cidadania, MDB, Pros, PSDB, PV e Rede; (iii) Esquerda: PcdoB, PDT, PSB, PSOL e PT. Na análise apresentada na próxima seção, então, comparamos a distribuição ideológica da autoria em relação a diferentes elementos do desenho da política social - esta, feita por meio da leitura do inteiro teor dos projetos e emendas.

Para além disso, sugerimos ainda que esse ponto é importante para compreender os futuros dividendos eleitorais que possam derivar desta e de outras políticas sociais. Diversos estudos mostram que o PT, por exemplo, se beneficiou, nas últimas eleições presidenciais, da distribuição de renda promovida pelo Programa Bolsa-Família (ZUCCO JR., 2015). Além de impactos positivos nas condições de vida da população pobre (CAMPELLO E NERI, 2013), os créditos eleitorais não prescindiram do fato de que o benefício está assentado em uma sólida estrutura institucional e de informação que, inclusive, possibilitaria, no futuro, a própria implementação da RBE (CARDOSO, 2020). Desde 2019, o governo Bolsonaro dá indicações de que pretende substituir o programa petista por um programa de sua autoria ${ }^{11}$. Mas foi a crise gerada no país pela pandemia de Covid-19 que trouxe à agenda política e legislativa brasileira a discussão sobre um novo programa de transferência. Nossa análise contribui ao chamar atenção para o fato de que os impactos distributivos de longo-prazo de uma nova política e, consequentemente, também os eleitorais, dependem das configurações de seu desenho e institucionalidade.

\section{A deliberação sobre a RBE}

Em meados de março, quando se iniciava a crise gerada pela pandemia de Covid-19, o ministro Guedes manifestou a intenção de conceder um auxílio emergencial no valor de $\mathrm{R} \$ 200,00$ para trabalhadores informais. $\mathrm{O}$ valor proposto tomava como base o benefício médio do PBF, e o novo programa seria paralelo à política iniciada no governo do $\mathrm{PT}^{12}$. No entanto, no dia 25 daquele mês, Rodrigo Maia (DEM/RJ), presidente da Câmara dos Deputados, se antecipa e pauta a discussão a partir do PL 9236 - que originalmente consistia em um conjunto de modificações propostas para o Benefício de Prestação Continuada (BPC), e que fora apresentado em 2017 por Eduardo Barbosa (PSDB/MG). O relator de plenário $^{13}$ designado por Maia, Marcelo Aro

\footnotetext{
${ }^{11}$ Ver, e.g., texto do Poder 360 (https://tinyurl.com/y6duetsg).

${ }^{12}$ Ver, e.g., texto do Uol Economia (https://tinyurl.com/y3xvuo6a).

${ }^{13}$ Notar que, extraordinariamente, as comissões deixaram de funcionar no regime de deliberação remota instituído devido à pandemia.
} 
(PP/MG), apresenta seu relatório no dia seguinte, incluindo os dispositivos que criam a RBE, o que denotou o interesse da Casa na rápida apreciação da matéria.

O parecer do relator propunha valor do benefício de $\mathrm{R} \$ 500,00$ por pessoa, com máximo de dois beneficiários por domicílio, incorporando também os inscritos no PBF. Ou seja, a proposta inicial capitaneada por Maia mais que dobrava a expectativa expressa pelo ministro da Economia. Naquele momento, diversos parlamentares de todos os espectros políticos indicavam em suas manifestações que haveria uma ampla maioria disposta a aprovar a medida. Observando esse movimento, o líder do governo Major Vitor Hugo (PSL/GO) anunciou então uma mudança na posição do governo:

Presidente Bolsonaro, muito sensível a esses 25 milhões de brasileiros, que são os mais afetados e mais sofridos, e atento às reivindicações dos Líderes partidários desta Casa, decidiu apoiar a medida de 600 reais [...]. Portanto, eu queria parabenizar a todos e dizer que essa não é uma vitória nem do Governo nem do Parlamento isolados: é uma vitória do Brasil como um todo.

Ou seja, antecipando que o auxílio seria aprovado com relativa facilidade, o governo inverteu a proposta restrita exposta por Guedes em prol de uma medida que poderia chegar a até $\mathrm{R} \$ 1.200,00$ em certos casos. Em resposta, Maia não deixou de chamar atenção para o protagonismo da Câmara na maior parte da articulação em prol da medida, além de pressionar pela aprovação presidencial:

Acho que é nesse ambiente de diálogo que o Parlamento sempre melhora os textos e as propostas que vêm do Governo. [...] E ficamos muito felizes, porque o mais importante para nós é que a proposta, ao sair daqui e do Senado, vá a sanção, não a veto.

O PL é aprovado de forma simbólica, sem nenhuma manifestação em contrário. Não obstante, algumas divergências mostraram-se presentes na proposição de emendamentos. Das 22 propostas de modificações sugeridas ao texto do relator, oito incidiam sobre os dispositivos da renda emergencial e duas propunham a criação de outros programas de transferência de renda com valores mais robustos e um maior número de parcelas (sendo uma proposta apresentada por um deputado do Podemos e outra pela bancada do PT).

A tabela abaixo mostra quais aspectos do desenho dessa política as emendas incidiam. Há, nela, especificação por ideologia do partido de seu autor: 
Tabela 1 - Emendas ao PL 9236/2020 - Câmara dos Deputados

\begin{tabular}{lccccccc}
\hline Câmara & Valor & Elegibilidade & Prazo & Implementação & $\begin{array}{c}\text { Política } \\
\text { nova }\end{array}$ & Fiscalização & TOTAL \\
\hline Esquerda & 2 & 2 & 0 & 0 & 1 & 0 & $\mathbf{5}$ \\
Centro & 0 & 2 & 0 & 0 & 0 & 0 & $\mathbf{2}$ \\
Direita & 0 & 2 & 0 & 0 & 1 & 0 & $\mathbf{3}$ \\
\hline TOTAL & $\mathbf{2}$ & $\mathbf{6}$ & $\mathbf{0}$ & $\mathbf{0}$ & $\mathbf{2}$ & $\mathbf{0}$ & $\mathbf{1 0}$ \\
\hline
\end{tabular}

Fonte: Elaboração própria a partir do site da Câmara dos Deputados.

Grande parte das emendas de elegibilidade dizia respeito à antecipação da RBE para os pleiteantes idosos que estivessem na fila do BPC, única alteração acatada pelo relator. Parlamentares de esquerda foram os únicos que defenderam valor superior a $\mathrm{R} \$ 600,00$ para o benefício, além da elevação do teto de renda de 2018 para uma pessoa ser considerável elegível, o que expandiria o número de beneficiários da política ${ }^{14}$. A prevalência da esquerda na proposição de emendamentos é ainda mais manifesta se compararmos com sua distribuição no plenário, composto por $57,2 \%$ de parlamentares vinculados a partidos de direita, $17,6 \%$ ao centro e $25,2 \%$ à esquerda. Apesar das manifestações em defesa de suas posições ${ }^{15}$, nenhuma emenda foi objeto de destaque.

Em suma, na primeira etapa de apreciação da matéria, a Câmara dos Deputados mostrou razoável disposição à aprovação de um auxílio emergencial, sem grandes conflitos expressos. Como veremos adiante, nas discussões sobre alterações no auxílio, clivagens mais claras iriam se manifestar.

A proposição chega ao Senado no dia 30 de março (Projeto de Lei ${ }^{\circ}$ 1066/2020), e é apreciada e aprovada no mesmo dia. O relator, Alessandro Vieira (Cidadania/SE), acolhe apenas emendas de redação, de modo a evitar que a matéria tenha que retornar à Câmara e, logo, que haja postergação no pagamento do auxílio ${ }^{16}$. As propostas feitas por seus pares no sentido de aumentar o escopo de beneficiários, a duração do benefício e os critérios de elegibilidade foram informalmente encaminhadas para um novo projeto de lei que alteraria a proposição que estavam então deliberando. A votação nominal da RBE no Senado mostrou novamente amplo apoio: 79 votos a favor e nenhum contrário.

Na Câmara Alta, grande parte dos pedidos de alteração consistia na explicitação de categorias profissionais elegíveis ao benefício, o que era juridicamente desnecessário, dado que os demais critérios permaneciam constantes ${ }^{17}$. Desconsiderando estas propostas e as emendas de redação, 18 emendas incidiam sobre o auxílio emergencial, conforme distribuição relatada na

\footnotetext{
${ }^{14} \mathrm{O}$ parlamentar do Podemos não se manifestou em favor de sua proposta de outra Renda Básica.

${ }^{15}$ Gleisi Hoffman (PT/PR), por exemplo, declarou: "Eu queria muito pedir (...) [para] esta Casa, rogar: vamos aprovar o valor de 1 salário mínimo".

${ }^{16}$ Com o fim de compreender a premência da pauta, cabe lembrar que naquele momento havia mais de um mês de registro do primeiro caso da doença no país, além de cerca de 15 dias da primeira morte.

${ }^{17}$ Ainda que possivelmente houvesse motivos políticos para tal, dado que diversos parlamentares relataram receber mensagens de categorias específicas preocupadas em não estarem aptas a receber o auxílio emergencial.
} 
tabela abaixo. Nela, vemos que a maior parte das iniciativas decorreu igualmente da ação de parlamentares de centro e de direita - não da esquerda, como ocorrera na Câmara:

Tabela 2 - Emendas ao PL 9236/2020 - Senado Federal

\begin{tabular}{lccccccc}
\hline Senado & Valor & Elegibilidade & Prazo & Implementação & $\begin{array}{c}\text { Política } \\
\text { nova }\end{array}$ & Fiscalização & TOTAL \\
\hline Esquerda & 0 & 1 & 0 & 1 & 0 & 0 & $\mathbf{2}$ \\
Centro & 0 & 6 & 0 & 2 & 0 & 0 & $\mathbf{8}$ \\
Direita & 1 & 5 & 1 & 1 & 0 & 0 & $\mathbf{8}$ \\
\hline TOTAL & $\mathbf{1}$ & $\mathbf{1 2}$ & $\mathbf{1}$ & $\mathbf{4}$ & $\mathbf{0}$ & $\mathbf{0}$ & $\mathbf{1 8}$ \\
\hline
\end{tabular}

Fonte: Elaboração própria a partir do site do Senado Federal.

Dentre as emendas apresentadas nesta etapa, destacam-se, por exemplo, a retirada do critério de renda em 2018 (critério ainda mais inclusivo do que o proposto pelo PT), a incorporação de mães menores de idade e o pagamento de duas cotas para pais solo. Além disso, quatro propostas incidiam sobre a implementação, aspecto que não havia aparecido na Câmara e que adiante se tornará preocupação principal do legislativo.

No dia primeiro de abril, Bolsonaro sanciona a lei com vetos parciais, um deles incidindo sobre a possibilidade de cessão da RBE, se constatado o descumprimento dos requisitos, com o argumento de que procedimentos necessários à apuração deveriam ser feitos uma única vez, no momento da concessão. Se na promulgação o governo aparentava não pretender dificultar a implementação do auxílio, o mesmo não se pode dizer do decreto 10.316/20 e da portaria 351/2020 que o regulamentaram. De acordo com essas normativas, todos os membros da família de pleiteantes não inscritos no CadÚnico deveriam ter inscrição no CPF regularizada. Além disso, o governo concentrou a operacionalização da RBE na Caixa Econômica Federal (CEF), descartando a utilização de outros bancos públicos e mesmo de unidades dos Centros de Referência de Assistência Social (CRAS). Como apontou o estudo da Rede de Pesquisa Solidária (2020b), tais medidas dificultaram o acesso inicial ao benefício particularmente para os mais vulneráveis, que possuem dificuldade com documentação, de acesso à internet (nada menos que 7,4 milhões de pessoas, só neste quesito) e de capacidade para realização de operações bancárias ${ }^{18}$.

Em suma, o comportamento dos parlamentares na apreciação congressual sobre a medida que institui a RBE foi muito pautado pela necessidade de aprovação célere, o que fez com que poucas desavenças emergissem. No entanto, propostas de mecanismos alternativos para a implementação, bem como elevações na magnitude do benefício e no prazo de duração foram objeto de disputa mais clara nos projetos que buscaram alteração da RBE.

\footnotetext{
${ }^{18}$ Para problemas apontados pelo estudo, ver, e.g., texto da Folha de S. Paulo (https://tinyurl.com/y74aetwx). Para contextualização dos aprimoramentos posteriores no modo de cadastramento, ver este outro texto da Folha de S. Paulo (https://tinyurl.com/y8vhsomu).
} 


\section{Preferências expressas nas propostas de alterações}

Alterações na RBE foram objeto de deliberações tão logo a medida foi aprovada pelo Congresso Nacional. No dia 31 de março, sob a relatoria de Esperidião Amim (PP/SC), 13 projetos de lei passaram a ser analisados conjuntamente, apensados ao PL n ${ }^{\circ} 873 / 20$ de autoria de Randolfe Rodrigues (Rede/AP), líder da minoria. No substitutivo do relator, apresentando no dia 2 de abril, a proposição que foi mais aproveitada foi o PL $\mathrm{n}^{\circ} 1.185 / 20$, de Vieira, que justamente compila todas as emendas apresentadas anteriormente na apreciação pelo Senado.

No texto de Amim, destacam-se como principais pontos: (i) a extinção do requisito de limite de rendimentos tributáveis recebidos em 2018, o que fora convertido pelo relator, em acordo com o governo, na obrigatoriedade de declaração da RBE na lista de rendimentos tributáveis caso o beneficiário venha a receber outros rendimentos que superem o valor da primeira faixa de rendimentos do Imposto de Renda no ano de 2020; (ii) o pagamento de duas cotas do auxílio à pessoa provedora de família monoparental, independente do sexo; (iii) a inclusão de mães com menos de 18 anos e, por fim, (iv) a extensão a todas instituições financeiras públicas das unidades subnacionais a possibilidade de operacionalização e pagamento da RBE, bem como de realização de transferência eletrônica para conta bancária de instituições não financeiras (tais como as fintechs). Incluiu-se também, na condição de correspondentes bancários, as agências lotéricas e dos Correios. Ou seja, o relatório ampliava a categoria de beneficiários, procurava facilitar a implementação do pagamento, mas criava uma penalidade para pessoas com rendimentos elevados em 2020.

Desconsiderando as emendas que simplesmente explicitavam o rol de categorias elegíveis e que propunham alterações de redação, 16 emendas propostas ao texto de Amim (dentre o total de 61) incidiam diretamente sobre o auxílio. Das 5 emendas que propunham programas novos, 4 incidiam em projetos apensados e propunham benefícios já contempladas pela RBE aprovada na Câmara. Destaca-se a prevalência do número de proposições da esquerda, principalmente as que se referem ao aumento de valor do benefício (todas são de autoria deste grupo) e ainda mais considerando sua menor distribuição no plenário: 13,9\%, em comparação com 49,4\% de senadores de partidos de direita e $36,7 \%$ de centro. 
Tabela 3 - Emendas ao PL 873 - Senado Federal

\begin{tabular}{lccccccc}
\hline $\begin{array}{l}\text { PL 873 - } \\
\text { Senado }\end{array}$ & Valor & Elegibilidade & Prazo & Implementação & $\begin{array}{c}\text { Política } \\
\text { nova }\end{array}$ & Fiscalização & TOTAL \\
\hline Esquerda & 4 & 2 & 2 & 1 & 0 & 0 & $\mathbf{9}$ \\
Centro & 0 & 4 & 0 & 1 & 3 & 0 & $\mathbf{8}$ \\
Direita & 0 & 0 & 1 & 1 & 2 & 0 & $\mathbf{4}$ \\
\hline TOTAL & $\mathbf{4}$ & $\mathbf{6}$ & $\mathbf{3}$ & $\mathbf{3}$ & $\mathbf{5}$ & $\mathbf{0}$ & $\mathbf{2 1}$ \\
\hline
\end{tabular}

Fonte: Elaboração própria a partir do site do Senado Federal.

O relator acatou, total ou parcialmente, 4 emendas: duas que buscavam facilitar a implementação e duas de ampliação da elegibilidade. Após a discussão, o Substitutivo ao Projeto de Lei $\mathrm{n}^{\circ} 873 / 20$ foi aprovado no dia 2 de abril, de forma unânime. No entanto, não deve ser superestimado o consenso parlamentar obtido neste caso.

A bancada do PT destacou para votação uma emenda de Rogério Carvalho (PT/SE), que propunha valor do benefício de 1 S.M. Em sua argumentação, o parlamentar lembrou que mesmo países como EUA, liderado (à época de sua fala) por Trump, propôs um auxílio mais robusto. Eduardo Braga (MDB/AM), vice-líder do governo, rechaça a ideia, relembrando que o valor do PBF é ainda menor que o do auxílio emergencial. O relator Amin também a critica, afirmando que se trata de um auxílio, e não de um salário ou remuneração. Álvaro Dias (Podemos/PR) completa: caso a emenda fosse aprovada, estaríamos "verificando que trabalhadores desempregados poderiam estar recebendo um valor superior ao de um trabalhador no exercício da atividade". Ao fim, a emenda proposta por Rogério Carvalho foi rejeitada por 51 votos a 22, com uma abstenção.

Observando a tabela abaixo, verifica-se uma clivagem clara na indicação dos líderes e no voto dos parlamentares entre as posições ideológicas: parlamentares de direita fortemente contrários ao aumento do benefício, os de esquerda favoráveis e os de centro se dividiram, com maioria contrária.

Tabela 4 - Votação ao destaque à emenda 47 - Senado Federal

\begin{tabular}{|c|c|c|c|c|c|c|c|c|}
\hline \multicolumn{9}{|c|}{ Emenda 47 - Senado } \\
\hline & \multicolumn{4}{|c|}{ Liderança } & \multicolumn{4}{|c|}{ Plenário } \\
\hline & Sim & Não & Libera & TOTAL & Sim & Não & Abstenções & TOTAL \\
\hline Esquerda & 2 & 1 & 0 & 3 & 10 & 2 & 0 & 12 \\
\hline Centro & 1 & 2 & 2 & 5 & 7 & 16 & 1 & 24 \\
\hline Direita & 0 & 8 & 0 & 8 & 5 & 33 & 0 & 38 \\
\hline TOTAL & 3 & 11 & 2 & 16 & 22 & 51 & 1 & 74 \\
\hline
\end{tabular}

Fonte: Elaboração própria a partir do site do Senado Federal. 
O projeto, então, foi encaminhado à Câmara dos Deputados, sob a relatoria de Cesinha da Madureira (PSD/SP), que apresentou seu parecer à deliberação no dia 16 de abril, apensando ao texto de origem do Senado outros projetos de lei. Como anteriormente, o texto base foi aprovado de forma simbólica. Da mesma forma, no entanto, muitas emendas foram apresentadas e a votação de destaques revela conflitos sobre aspectos relevantes do auxílio.

Os deputados apresentaram o total de 70 emendas nesta fase da tramitação. Novamente, excetuando-se as emendas que propunham apenas alterações de redação ou a inclusão de categorias de usuários já contempladas pela versão prévia da lei, restam 29 emendas com incidência direta sobre o auxílio. Cabe destacar que o relator acatou, integralmente ou em parte, oito delas, sendo duas sobre elegibilidade e seis sobre o tema da implementação, a exemplo daquela que suprimiu a obrigação do beneficiário declarante do IR de acrescentar o valor do auxílio emergencial na lista de rendimentos ${ }^{19}$.

Tabela 5 - Emendas ao PL 873 - Câmara dos Deputados

\begin{tabular}{lccccccc}
\hline $\begin{array}{l}\text { PL 873 - } \\
\text { Câmara }\end{array}$ & Valor & Elegibilidade & Prazo & Implementação & $\begin{array}{c}\text { Política } \\
\text { nova }\end{array}$ & Fiscalização & TOTAL \\
\hline Esquerda & 0 & 3 & 0 & 21 & 2 & 0 & $\mathbf{2 6}$ \\
Centro & 0 & 0 & 0 & 0 & 0 & 0 & $\mathbf{0}$ \\
Direita & 0 & 5 & 0 & 0 & 0 & 0 & $\mathbf{5}$ \\
\hline TOTAL & $\mathbf{0}$ & $\mathbf{8}$ & $\mathbf{0}$ & $\mathbf{2 1}$ & $\mathbf{2}$ & $\mathbf{0}$ & $\mathbf{3 1}$ \\
\hline
\end{tabular}

Fonte: Elaboração própria a partir do site da Câmara dos Deputados.

Salta aos olhos nesse subconjunto de 29 emendas a proeminência dos pedidos de alteração submetidos por parlamentares de esquerda, particularmente sobre mecanismos de implementação. Um de seus exemplos mais significativos se refere à disputa acerca da necessidade ou não de regularização do CPF para recebimento do auxílio, assim como acerca da forma de cadastramento e/ou apoio aos beneficiários.

A exigência de regularização do CPF para fins de recebimento da RBE causou alvoroço pelo País e corroborou para a formação de grandes filas nas agências da CEF e da Receita Federal no mês de abril, em que imperava a necessidade de cumprimento das políticas subnacionais de isolamento social ${ }^{20}$. Essa questão foi, inclusive, alvo de controvérsia judicial ${ }^{21}$. Parlamentares da oposição relembram que decisões na primeira instância do Judiciário retiraram a exigência de posse do CPF, no entanto, como reforça José Guimarães (PT/CE) "o que fez o Governo Bolsonaro? Recorreu da decisão". A Câmara aprovou, por votação simbólica, um destaque do

\footnotetext{
${ }^{19}$ Considerou-se esse aspecto da política como implementação, ainda que a posteriori ele incida no valor do benefício auferido.

${ }^{20}$ Ver texto no G1 (https://tinyurl.com/y24hqwcb).

${ }^{21}$ Ver texto no G1(https://tinyurl.com/y2e8wpat).
} 
PSB e outro do PSOL $^{22}$ que alteraram o texto do relator, flexibilizando mecanismos de regularização da documentação. Ainda que parlamentares governistas, como Caros Jordy (PSL/RJ), destacassem que "muitos relatos começaram a surgir de pessoas mal-intencionadas, presidiários e criminosos fazendo de maneira oportunista o uso de CPFs irregulares para obterem esse auxílio de forma fraudulenta", mesmo o líder do governo Vitor Hugo afirma que "reconhecendo a preocupação com o problema por parte dos diversos partidos do Parlamento, não só de esquerda, mas de centro, de centro-direita e de direita, o Governo vai orientar 'sim"”, revelando novamente um comportamento dúbio por parte do governo quanto à facilitar ou dificultar a implementação do auxílio.

Mesma sorte não teve outro destaque levantado pelo PT que permitiria que entidades vinculadas ao Sistema Único de Assistência Social (SUAS), além dos CRAS, fizessem cadastro de beneficiários pela internet, inclusive com busca ativa ${ }^{23}$, possibilitando que o mesmo telefone e computador pudessem ser usados para cadastrar várias pessoas. Paulo Teixeira (PT/SP) defendeu o destaque, afirmando que essa medida permitiria, dentre outros ganhos, o acesso à renda dos moradores de rua e dos indígenas - cabe mencionar, tal impacto poderia ser ainda maior se considerada a dificuldade de acesso à internet vivenciada por milhões de brasileiros. Entretanto, o líder do governo encaminhou voto contrário, afirmando que "o governo acha que isso pode precarizar as relações e aumentar o número de fraudes".

Como mostra a tabela abaixo, tem-se uma clara divisão ideológica no encaminhamento e no voto.

Tabela 6 - Votação ao destaque à emenda 64 - Câmara dos Deputados

\begin{tabular}{lccccccccc}
\hline & \multicolumn{1}{c}{ Emenda 64-Câmara } \\
\hline & \multicolumn{1}{c}{ Lim } & Não & Libera & TOTAL & & Sim & Não & Abstenções & TOTAL \\
Esquerda & 5 & 0 & 0 & 5 & & 121 & 3 & 0 & 124 \\
Centro & 2 & 3 & 1 & 6 & & 29 & 48 & 0 & 77 \\
Direita & 3 & 10 & 0 & 13 & & 31 & 240 & 1 & 272 \\
\hline TOTAL & $\mathbf{1 0}$ & $\mathbf{1 3}$ & $\mathbf{1}$ & $\mathbf{2 4}$ & & $\mathbf{1 8 1}$ & $\mathbf{2 9 1}$ & $\mathbf{1}$ & $\mathbf{4 7 3}$ \\
\hline
\end{tabular}

Fonte: Elaboração própria a partir do site da Câmara dos Deputados.

Com as alterações empreendidas na Câmara, o texto retorna ao Senado e no dia 22 de abril passa pela última revisão. Novamente, Amim foi o relator. Nesta fase do processo legislativo, não cabem novas alterações ao texto. O que se pode é aceitar ou rejeitar as

\footnotetext{
${ }^{22}$ Apenas as lideranças do NOVO e do PSL indicaram voto contrário a cada uma dessas medidas, respectivamente.

${ }^{23}$ Ver fala de Renata Bichir no Uol (https://tinyurl.com/y4jijaj89).
} 
modificações feitas pela Casa legislativa anterior, ou resgatar emendas protocoladas anteriormente.

O substitutivo retoma a proposta original aprovada pelo Senado de tributação da RBE. Além disso, o relator acatou o requerimento feito pelo líder do governo Fernando Bezerra Coelho (MDB/PE) que derrubava a extinção da exigência de CPF aprovada pela Câmara. Nas palavras de seu autor: "trata-se de dispositivo que favorece a atuação de fraudadores do RBE". Ambos os casos foram alvos de requerimentos que solicitavam a aceitação do texto da Câmara. No entanto, as manifestações dos parlamentares revelavam que havia uma intenção de votar ainda naquela sessão o Substitutivo e encaminhá-lo para a sanção presidencial o quanto antes, pois, como declara Weverton (PDT/MA), "nós sabemos que, quanto mais rápido for aprovado esse projeto, mais rápido ele vai chegar na Presidência para poder sancionar. Temos milhões de brasileiros que estão precisando". Os destaques são retirados e a medida foi aprovada no Senado Federal por unanimidade.

Na contramão do timing da apreciação pelo parlamento, Bolsonaro postergou ao máximo sua decisão, sancionando com veto parcial a medida no dia 14 de maio. Foram vetados, dentre outros aspectos: o valor de $\mathrm{R} \$ 1.200$ para pais solos a cumulatividade da RBE com o BolsaFamília e a exclusão do limite de R $\$ 28.559,70$ de renda em 2018 como critério de elegibilidade. Ou seja, das alterações de monta propostas ao auxílio, restou apenas a inclusão de mães menor de idade $^{24}$.

Em suma, se na aprovação da RBE os parlamentares buscaram a celeridade, conflitos maiores expressaram-se no projeto que a alterou. E o quadro é claro: a esquerda buscou aumentar o valor e criar mecanismos de implementação que vinculassem a implementação da política ao SUAS. A direita e o governo foram contrários a essas medidas, assim como ao aumento de elegíveis.

\section{Projetos em tramitação}

Os três meses de prazo inicial de concessão do auxílio encerraram-se no final de junho. A lei permite ao presidente prorrogar o benefício unilateralmente, mantendo componentes essenciais da política pública. Bolsonaro, então, decretou a prorrogação por mais dois meses. Desde a promulgação da lei até este decreto, ao menos 93 projetos de lei ou de decreto legislativo que incidiam sobre a RBE foram protocolados na Câmara ou no Senado, o que dá uma média de mais de um projeto por dia corrido ${ }^{25}$.

\footnotetext{
${ }^{24}$ No dia 4 de novembro, o Congresso manteve os vetos do executivo.

${ }^{25}$ Nossa busca ateve-se ao período compreendido entre a publicação da Lei ${ }^{\circ} 13.982 / 20$ e do Decreto ${ }^{\circ} 10.412 / 20$, e usou as seguintes palavras-chave: "renda básica", "renda básica emergencial", "Lei 13.982", e "auxílio emergencial". Do resultado dessa busca, ocupamo-nos em levantar apenas os projetos parlamentares que originalmente, em seu texto
} 
A tabela abaixo - que detalha em quais aspectos os projetos incidem (podendo ser mais de um, pois isso valor maior que 93) - mostra que parlamentares vinculados à esquerda eram autores da maioria das proposições. O único parâmetro no qual a esquerda não foi majoritária diz respeito a mecanismos de fiscalização e punição ao beneficiário irregular, categoria na qual a direita se sobressai. Grande parte das propostas incidem sobre arranjos da implementação ou sobre a prorrogação do prazo de vigência do auxílio. Este último quesito, inclusive, foi o que mais recebeu atenção de partidos do centro. Alterações nas regras de elegibilidade também estiveram fortemente presentes e, em menor grau, os projetos referidos à elevação do valor do benefício.

Tabela 7 - Projetos de lei e de decretos legislativos relacionados à RBE - Câmara dos Deputados e Senado Federal

\begin{tabular}{lccccccc}
\hline $\begin{array}{l}\text { Projetos } \\
\text { posteriores }\end{array}$ & Valor & Elegibilidade & Prazo & Implementação & $\begin{array}{c}\text { Política } \\
\text { nova }\end{array}$ & Fiscalização & TOTAL \\
\hline Esquerda & 6 & 13 & 20 & 27 & 3 & 2 & $\mathbf{7 1}$ \\
Centro & 1 & 4 & 6 & 3 & 2 & 0 & $\mathbf{1 6}$ \\
Direita & 1 & 1 & 9 & 11 & 0 & 4 & $\mathbf{2 6}$ \\
\hline TOTAL & $\mathbf{8}$ & $\mathbf{1 8}$ & $\mathbf{3 5}$ & $\mathbf{4 1}$ & $\mathbf{5}$ & $\mathbf{6}$ & $\mathbf{1 1 3}$ \\
\hline
\end{tabular}

Fonte: Elaboração própria a partir do site da Câmara dos Deputados e do Senado Federal.

De todas essas propostas, apenas uma, até o momento de escrita deste texto (nov/2020), foi aprovada pelo Congresso (apensando outras duas proposições). Trata-se de uma proposta de origem na Câmara com coautoria de diversos parlamentares de esquerda, que estendia o duplo pagamento a pais solo, e que garantia primazia à mulher quando pai e mãe solicitavam benefício separadamente. No final de julho, entretanto, o executivo vetou totalmente o projeto ${ }^{26}$.

\section{Conclusões}

O Congresso foi o principal ator responsável pela articulação e célere aprovação do auxílio emergencial. A criação deste programa social ensejou a formação de uma Frente Parlamentar da Renda Básica, composta por quase metade do congresso, de praticamente todos os partidos (exceto o Novo). Projetos foram apresentados por parlamentares de diversas posições políticas, como Eduardo Braga (MDB/AM), José Serra (PSDB/SP), Randolfe Rodrigues

inicial, tratavam de algum tópico sobre a RBE. Para tanto, examinamos as ementas e o teor dos projetos e selecionamos aqueles que tinham relação com esse programa social.

${ }^{26}$ Cabe sublinhar que, a partir da tramitação do $\mathrm{PL} \mathrm{n}^{\circ} 873 / 20$, apresentada no item anterior, e da tramitação deste projeto ( $\left.\mathrm{PL} \mathrm{n}{ }^{\circ} 2508 / 20\right)$, que a concessão de 2 quotas de RBE para pais solo era um ponto de divergência entre os poderes, pois o Poder Executivo teve de usar duas vezes, em momentos bastante próximos um do outro, o veto contra a investida do Congresso Nacional para inserir essa pauta no quadro jurídico da RBE. 
(REDE/AP) e Paulo Paim (PT/RS). Mas é possível dizer que existiu um consenso legislativo a favor dessa questão?

Mostramos neste artigo que a deliberação sobre o auxílio emergencial revela conflitos de preferências sobre diversas características da política social. Particularmente, a esquerda foi mais atuante na defesa de um benefício de maior valor e prazo, mais facilidade na implementação e expansão nos critérios de elegibilidade - propostas que muitas vezes não foram acatadas por parlamentares de direita. Ou seja, a defesa de um programa de transferência de renda pouco diz sobre os elementos específicos do desenho dessa política, elementos esses com importantes consequências sociais e econômicas.

Além dos impactos socioeconômicos, o auxílio emergencial chama atenção pelas suas consequências políticas. É disseminada a opinião de que Bolsonaro estaria colhendo dividendos eleitorais da RBE. Esta visão parte do suposto de que, bastaria o governo implementar a política para ser favorecido, mesmo que, como mostrado aqui, não seja autor da medida, dificulte sua implementação e vete sua expansão. Ou seja, nessa visão, o eleitorado seria, em grande medida, indiferente ao comportamento dos atores políticos. Debatendo e contrariando essas premissas, Simoni Júnior (2019) argumenta que o PT conseguiu se beneficiar mais do Bolsa-Família que o PSDB do Bolsa-Escola pois se mobilizou em torno da pauta, com iniciativa e liderança legislativa ${ }^{27}$. Mais do que isso, o partido continuaria recebendo dividendos eleitorais mesmo depois de ter perdido o controle da implementação do programa.

Assim, chamamos atenção para algumas notas de cautela sobre o retorno político do auxílio. Em que pese a visão disseminada, não é muito clara a magnitude do impacto da renda emergencial na popularidade de Bolsonaro ${ }^{28}$. O presidente combina discursos de credit-claiming $^{2}$ da política com alertas de que não é possível mantê-la dado seu custo fiscal ${ }^{29}$. Após expiração de sua vigência, em setembro o governo editou a MP que criava um "Auxílio Emergencial residual" com pagamentos de R $\$ 300$ mensais (até 31 de dezembro). Essa estratégia visou contornar a participação do Congresso, o que seria inevitável se desejasse alterar a lei original da RBE. Desde então, a estratégia de partidos de esquerda consiste em obstrução para pautar a MP, com o objetivo de aumentar o valor das parcelas ${ }^{30}$. Por que a oposição adotaria tal estratégia se Bolsonaro usufruísse de todos os créditos políticos?

Consideramos que não é adequado tratar a relação entre política social e preferências eleitorais de maneira demasiado simplista: afinal, findo o auxílio, eleitores podem se balizar em

\footnotetext{
${ }^{27}$ Foi o PFL (hoje DEM) que liderou a aprovação da PEC do Fundo de Combate à Pobreza e relatou a Medida Provisória (MP) do Bolsa-Escola.

${ }^{28}$ Ver texto de Marta Arretche (https://tinyurl.com/y3s88deu) e falas de Cesar Zucco e Natália Sátyro, todos no Nexo (https://tinyurl.com/y56ulxbv), assim como falas de vários pesquisadores no DW (https://tinyurl.com/y9qlvogy).

${ }^{29}$ Ver texto do Valor (https://tinyurl.com/y2vywv5z)

${ }^{30}$ Ver texto do UOL Economia (https://tinyurl.com/y57yd2xs). $70 \%$ das emendas apresentadas à MP vieram de partidos de esquerda.
} 
decisões e posicionamentos políticos dos partidos para guiar seu comportamento de punição ou recompensa.

\section{Referências bibliográficas}

ARAÚJO, Victor. Mecanismos de alinhamento de preferências em governos multipartidários: controle de políticas públicas no presidencialismo brasileiro. Opinião Pública, v. 23, n. 2, p. 429458, 2017.

BARBOSA, Rogério; PRATES, Ian. Efeitos do desemprego, do Auxílio Emergencial e do Programa Emergencial de Preservação do Emprego e da Renda (MP 936) sobre a renda, a pobreza e a desigualdade durante e depois da pandemia. IPEA - Boletim Mercado de Trabalho Conjuntura e Análise, n.69, p. 65-79, julho 2020.

CAMPEllo, T.; NERI, M. C. (org.). Programa Bolsa Família: uma década de inclusão e cidadania. Brasília: Ipea, 2013.

CARDOSO, Bruno Baranda. A implementação do Auxílio Emergencial como medida excepcional de proteção social. Revista de Administração Pública, v. 54, n. 4, p. 1052-1063, 2020.

CECCHINI, S.; MADARIAGA, A. Programas de Transferencias Condicionadas. Balance de la experiencia reciente en América Latina y el Caribe. Santiago de Chile, CEPAL, 2011.

CODATO, Adriano; BERLATTO, Fábia; BOLOGNESI, Bruno.Tipologia dos políticos de direita no Brasil: uma classificação empírica. Análise Social, v. 4, n. 229, 2018.

FIGUEIREDO, Argelina; LIMONGI, Fernando. Poder de agenda e políticas substantivas. In: RENNÓ, L.; INÁCIO, M. (ed.). Legislativo brasileiro em perspectiva comparada. Belo Horizonte: Editora UFMG, p. 77-104, 2009.

FREIRE, D.; DOMINGUES, E.; MAGALHÃES, A.; SIMONATO, T.; MIYAJIMA D. Renda Básica Emergencial: uma resposta suficiente para os impactos econômicos da pandemia da COVID-19 no Brasil?. Nota Técnica de maio de 202. Disponível em https://tinyurl.com/y2neqzlx. Acesso em: 10 nov. 2020.

FRISZBEIN, A.; SCHADY, N. Conditional cash transfers reducing present and future poverty. Washington D.C: Banco Mundial, 2009.

FREITAS, Andréa. O presidencialismo da coalizão. Rio de Janeiro: Fundação KonradAdenauer, 2016.

INÁCIO, Magna; REZENDE, Daniela. Partidos legislativos e governo de coalizão: controle horizontal das políticas públicas. Opinião Pública, v. 21, n. 2, p. 296-335, 2015.

IZUMI, Maurício. Governo e Oposição no Senado Brasileiro (1989-2010). Dados:Revista de Ciências Sociais, v. 59, n.1, p. 91-138, 2016.

LOWI, Theodore J. Four Systems of Policy, Politics and Choice. Public Administration Review, v. 32, n. 4, 1972. 
REDE DE PESQUISA SOLIDÁRIA. Covid-19: Políticas Públicas e as Respostas da Sociedade. Nota Técnica No. 14 - Situação dramática do desemprego está oculta nos indicadores oficiais. Sem renda emergencial de $\mathrm{R} \$ 600,00$ a pobreza atingiria 30\% da população, 2020a. Disponível em: https://tinyurl.com/y5awo22t. Acesso em: 10 nov. 2020.

REDE DE PESQUISA SOLIDÁRIA. Covid-19: Políticas Públicas e as Respostas da Sociedade. Nota Técnica No. 5 - Dificuldades com aplicativo e não uso da rede de proteção atual limitam acesso ao auxílio de emergência, 2020b. Disponível em: https://tinyurl.com/yykq5nfe. Acesso em: 10 nov. 2020.

SHEPSLE, Kenneth. Congress Is a "They," Not an "It": Legislative Intent as Oxymoro. International Review of Law and Economics, n. 12, p. 239-256, 1992.

SIMONI JÚNIOR, Sergio. Dividendos eleitorais de políticas programáticas: O caso do BolsaEscola e do Bolsa-Família. In: ENCONTRO ANIAL DA ANPOCS, 43., 2019. Anais [...].

ZUCCO JR., Cesar. The Impacts of Conditional Cash Transfers in Four Presidential Elections (2002-2014). Brazilian Political Science Review, v. 9, n. 1, 2015. 